\title{
Chinese Megablock Urbanism
}

\section{a Tool of Limitless Urbanization at an Unprecedented Speed and Scale}

Yixuan PENG, The Hong Kong Polytechnic University; Hong Kong, China

Gerhard BRUYNS, The Hong Kong Polytechnic University; Hong Kong, China

Darren NEL, The Hong Kong Polytechnic University; Hong Kong, China

\begin{abstract}
In what way can the study of megablock typologies in the PRD deliver better insight in terms of process and scales of Chinese urbanization?

In the Chinese context, the 'collective' has stood central to its urbanisms and processes of urbanization (Lu, 2006). As a state where ownership and territoriality are retained by a socialist system, the basic elements of this (urban) model have remained the creation of collective housing founded on publicly owned land. From the 'neighbourhood-unit' (邻里单位) and 'working-unit' (单位大院), to 'commodity housing' (商品房) (Lu, 2006), these practices gradually shape Chinese cities in "Socialism with Chinese characteristics" into what can only be termed 'megablock' urban fabrics.

Where, 'Mega' infrastructure in cities, or better yet, megablocks, embody the antithesis of open and transparent entities. Beyond its organization with the physical network (transportation or public service), they impact the urbanization process in terms of speed and scale. The Chinese urban population has risen from 18\% in 1978 to 58.5\% in 2017 (National Bureau of Statistics of China, 2018). Between 1991 and 2000, 83\% of Shanghai's residential compounds became enclaves, with the Guangdong Province alone witnessing the formation of 54,000 closed-off compounds, covering more than $70 \%$ of the city surface and housing more than $80 \%$ of its population (Miao, 2004).

Broadly speaking, former and ongoing studies of Chinese urbanization are yet to provide a clear perspective of megablock development, both in terms of the unprecedented context and its spatial impact.

This paper aims to address concerns pertaining to the megablock phenomenon: its impacts on urban morphology as well as its prevalent strategies as an urban model. The argument presented here hopes to touch upon the links between planning and the eventual morphological expression of megablock development, and possibly argue for the cultivation of an urbanization practice that needs to become systematic in its sustainable focus and outcomes.
\end{abstract}

Key words

Chinese megablock urbanism, scale, rapid urbanization

\section{Introduction}

There is no denying the significance of understanding "scale" in urban studies in China (Miao, 2013). In either daily life or theoretical analysis, the 'mega' scale has become part and parcel of the Chinese context intuitively observed by researchers, citizens or even outsiders as a key and foundational role in all dimensions and formats of urban issues. However, scale, at the same time, is often overly underestimated in many studies of Chinese urbanization. 
When examining the form of Chinese urbanism and its spatial organization, one should understand both the meaning and roles of scale and its mechanization in any type of urban development. This brings in its wake other questions that pertain to whether the elements of scale can be fully conceptualized and theorized to act as the basic conceptual framework and analytical tools for analyzing the historical conditions pertaining to Chinese urban form as well as future trajectories of Chinese urbanisms and their evolution processes. In addition, it questions whether it is possible to conduct a secondary level of research that can reveal the opportunities and threats of this 'scalar' model, not only applicable to the Chinese context but also relevant to other urban settings elsewhere. Moreover, what perspectives are implicitly hidden behind the study of Chinese mega scale? The above questions would ultimately lead to the study of the "ultra-large-bigness" as a factor for accessing all formats of Chinese urban forms.

In traditional Western philosophy, relatively, the size of a city or country should be controlled to a reasonable scale. Plato had a thorough discussion about the size of the polis which has been regarded as one of the most classical and influential theoretical frameworks in understanding Western cities. Plato's The Republic (380 B.C.) regards the expansion of the city-state as the ultimate cause of the segmentation between the rich and the poor, or political factions within the city. In his view, the polis is suitable to be built in a place that is neither too close nor too far to the port and the population size should be around 20,000. Aristotle further agreed with Plato's opinion that cities should not expand too far away from their designated scale. Therefore, when the size of a polis is too large, some sort of procedure would be required to redistribute the populous to form another secondary polis, so that the size of the city-state can always be kept to an appropriate size.

Inherited with such concepts of social organisms and their limits, the Western perception has difficulty in digesting the material dimensions when observing Chinese city scales. They seem to be unfamiliar with this civilization form, almost equivalent in size to an entire European territory, that has already functioned and operated as a territorial 'unit' for more than a thousand years. This scale challenges the urban philosophy and common sense of Western scholars. As a result, the perception and interpretation of "ultra-large-scale" have emerged.

The majority of existing studies place more emphasis on the challenges and complexity that scale brings to China's urban problems (Wang \& Zhang, 2016). When examining and discussing China's super-large scale, many researchers would often state that due to China's huge scale and volume, the urban space remains "big and unreasonable" (Ibid). As such, the basic research paradigm is to appropriate the various criteria of "normative urban morphology" to investigate the challenges and difficulties that are brought about by the "ultra-large-scale" tolerance and function in the conventional spatial scales (Guo, 2019). Based on this typology, a large number of Chinese urban special theories are built upon this or its extension.

The broader framework of this research starts touching upon the question of Chinese 'mega' scale as a discernible scale paradigm. The assumption is based on the following three facts: firstly, the mega scale is inherited from the traditional city-state ideology evident from the historical project; secondly, the socialist public system of the New China has by default had to address the mega phenomena as part of its social-spatial mandate; thirdly, China remains the world's most populated country resulting in the majority of the territorial strategies being mega developments. Collectively these contribute to rethinking the question of scale, more specifically the impact of how and in what terms the 'mega' is utilized in the Chinese context. 
Focusing on its radicalness of speed and scale, this paper specifically aims to investigate the formative and material definitions of Chinese mega-development at the urban block scale. Two cases are highlighted of what is defined as Chinese megablock urbanism (CMU), as a model of Pearl River Delta (PRD) urban agglomeration. As such, CMU has become instrumental, as a tool of limitless urbanization, that as yet remains undefined.

\section{Background of Chinese Megablock Urbanism}

\subsection{Definition of "Megablock"}

Scale is a fundamental requirement for urban study. Not only is scale essential for conceiving actual proposals and projects, but it remains crucial to inform the diversity of spatial nomenclatures to comprehend and access space itself. The term "Mega" has been widely used in describing spatial forms. In the domain of architecture, $S, M, L, X L$ by Rem Koolhaas and Bruce Mau (1995), weaves together OMA projects according to "size", challenging conventional understanding of architecture, scale, and the city. Examples listed within the 'size' category are: small - Villa Dall'Ava, St. Cloud, Paris, 1991; medium Kunsthall, Rotterdam, 1992; large - Congrexpo (Lille Grand Palais), Lille France, 1994; and extra-large - Bijlmermeer Redevelopment, Amsterdam, 1986 (see Table 1). Koolhaas discusses 'Bigness' in an intriguing way:

"Beyond a certain scale, architecture acquires the properties of Bigness. ... Of all possible categories, Bigness does not seem to deserve a manifesto; discredited as an intellectual problem, it is apparently on its way to extinction - like the dinosaur-through clumsiness, slowness, inflexibility, difficulty. But in fact, only bigness instigates the regime of complexity that mobilizes the full intelligence of architecture and its related fields." (Koolhass and Mau, 1995, p495-497).

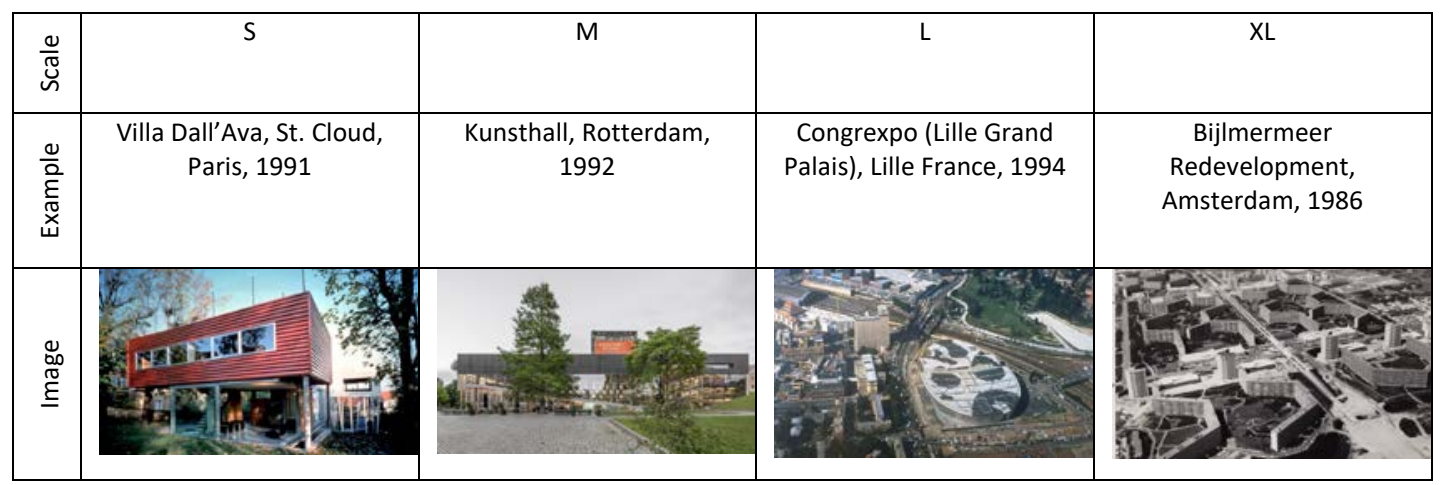

Table 1. Examples of architectural projects classified by the scale of $S, M, L, X L$ by Rem Koolhaas and Bruce Mau (1995)

Moreover, the use of "mega" as a descriptive term is more commonly associated with overall city definition and not sub-components of what constitutes the city. We trace the origins of the concept of 'mega' to Patrick Geddes (1915). Later the concept was repackaged into the term 'megalopolis' referred to first by Spengler (1918) and later by Lewis Mumford (1938) in Lewis' book The Culture of Cities. Lewis uses the megalopolis to describe the excessive development and expansion of cities, and how this has direct bearings on the decline in social quality. Mumford provides six stages in the growth of a city: 1. Eopopis, 2. Polis, 3. Metropolis, 4. Megapolis, 5. Tyrannopolis, and 6. Necropolis. They all refer to single entities as cities operating and functioning under their own operative logic. In more recent definitions, the United Nations (2014) defines each 'megacity' as urban agglomerations that exceed 10 million inhabitants. This essentially shifts the meaning from a single-entity reading 
of the mega into a dimension of multiple territories as parts of mega and urban development.

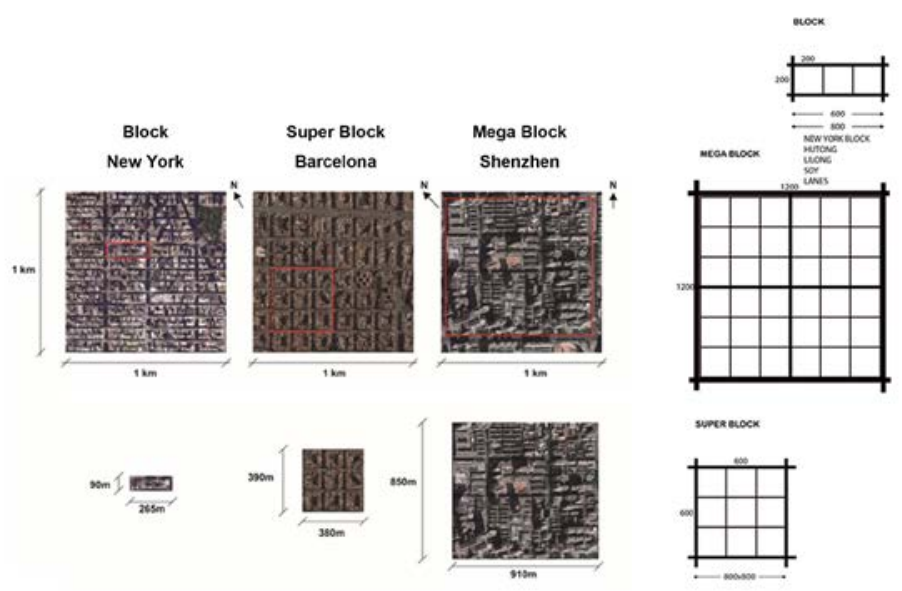

Figure 1. Diagram of a block-superblock-megablock. Left: aerial photos of New York block, Barcelona superblock and Shenzhen megablock. Right: diagram of the block system from Shane 2014. Source: author; Shane (2014)

Shifting focus to the intermediate scale; more specifically, between building and city, at the level of street block; the concept of "mega-block" has been widely mentioned. Still, 'mega' and its relation to the 'block', something we postulate as the 'megablock', remains undefined in its actual properties of morphological characteristics. An urban block can be defined as a plot of land enclosed by streets (definition by for example Code of Urban Residential Areas Planning \& Design GB50180-2018). A block system is commonly seen as the model that differentiates urbanized from unurbanized area development. Adopting the block principle, urban blocks allow buildings to be located along the perimeter of blocks with entrances facing streets, which attempts to provide ideal social interactions between people (Frey, 1999). Block development is referenced by a variety of scholars. For instance, Alzraikat (2016) indicated a changing capacity and scale of urban organization over time associated with terms such as block, superblock, and megablock. Accompanied with the growth of cities, an urban hierarchy is defined by block sequences. While Siksna (1997) conducted research on the effects of block size and form with samples from North America and Australia. Shane (2014) defined the enlarging and nesting blocks by the city's expansion. He demonstrated

"The scale of the block dimensions shifted over time, enlarging its area from its small scale-early beginnings with 1.6acre blocks in grid formations, to 16acre super blocks to 160 acre or more megablocks". (Shane, 2014. see Figure 1).

\subsection{Urbanization at an Unprecedented Speed}

In general, urbanization is divisible into three stages according to the level of development: 1 . initial period, 2. rapid development period and 3. stable saturated period (Zhu, 2004). Empirical studies in Western urban planning and development processes have demonstrated that the focus of urban planning corresponds to its urbanization level (Tortora et al., 2015). In 1978, accompanied by the economic reformation and opening-up policies, China's first national urban planning guideline emphasized acceleration of the urbanization process. At a global scale this remains unprecedented. In the past four decades, China experienced the largest and fastest industrialization and urbanization process in the history of the world. From 1978 to 2017 (38 years), China's urbanization rate increased from $17.9 \%$ in 1978 to $58.5 \%$ in 2017 (40.6\% growth), with the number of permanent residents in urban areas increasing from 170 million to 810 million (476.47\% growth) (National Bureau of Statistics of 
China, 2018). Echoed within the urban dimension, this accounts for roughly 40 years of reform that was accompanied by four decades of radical Chinese urbanization (see Figure 2).

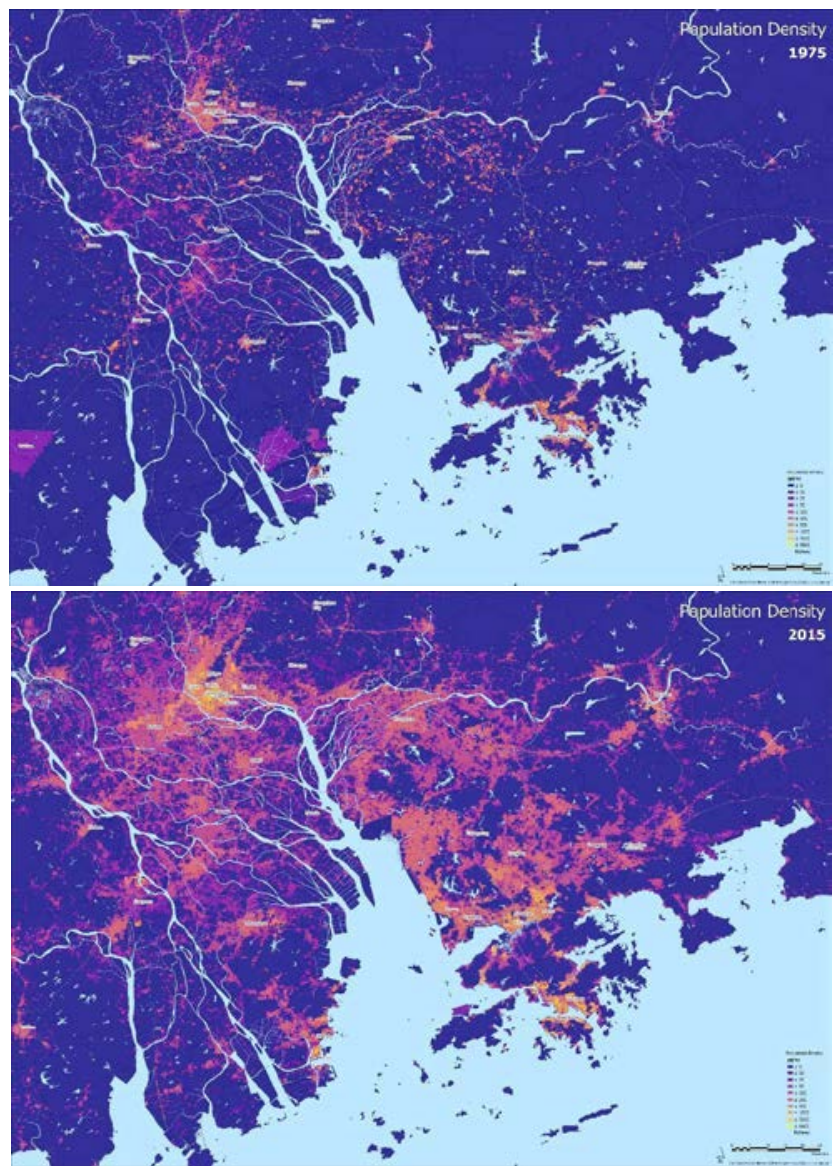

Figure 2. Forty years' urban population density change in the PRD, left: 1975, right: 2015. Source: data from GHS and maps from author.

In a 'modern' sense, radical and mega conditions of Chinese urbanization have emerged with distinct characteristics evident in its spatial and morphological complexes. Rapid urbanization in the Chinese context, starting from the Reform and Opening-up in 1978 has shown levels of urban growth, leaping from $17.9 \%$ to $40.5 \%$ in 2003 . China's 'Great Leap Forward of City' in 25 years, has reached the level of urbanization (from $20 \%$ to $40 \%$ ) equivalent to what The United Kingdom achieved over 120 years, or the United States over an 80-year period (Yin, 2010, p2). After 1992, which is the year the official market economy replaced the former planned economic incentives, Chinese urbanization accelerated to $1.2 \%$ per year (three times the world's average in the same period (Ibid)).

\subsection{A Tool of limitless Urbanization in Terms of Scale}

To achieve this unprecedented rapid urbanization, interventions and new tools are indispensable. Globally, there is a growing phenomenon that is being discussed under the heading of "Big Plans" as stated by Kolson (2001). From the changing nature of urbanization in scale, we witness other qualities emerging in the Chinese context. For example, it has become standard practice for Chinese planning to develop a megacity that is six times larger than Paris or ten times that of London (Li \& Li, 2006). Within the framework of big-plan, the development of mega urbanization requires the incorporation of surrounding villages or adjacent cities as part of one administrative boundary. As a consequence, mega-projects entitled 'development districts' (开发区), 'new towns' (新城), 'university towns' (大学城), oversize plazas, lawns, infrastructures, amongst others, courbanize (Yin, 2010), pushing 
megablock development as the dominant form of planned urbanization. Within the 'Great Leap Forward' context, urbanization relies on a housing model that has shifted from the planned work unit into market-driven real estate. Megablocks claim the titles of the "largest compound in China", and constantly surpass the sizes and scales of conventional planning in a Western sense. For instance, the Clifford Estate (CE) developed in the 1990s captures 100,000 residents within $5 \mathrm{~km}^{2}$, with the Huaguoyuan development in the 2010s capturing 420,000 residents in $4 \mathrm{~km}^{2}$. If we compare the scale of urban blocks in China with other big cities around the world, the differences are evident (see Figure 3).

Compared to European cities of the same period, Chinese city blocks have always been much larger, in both ancient times (Guo, 2019) and after the 1949 establishment of the People's Republic of China (PRC). Existing models of development easily exceed more than 20 hectares, which is regarded as a tribute to the ancient Lifang (里坊, neighbourhood) system (Sun \& Liang, 2003). The adaptation of the Soviet Union's models of 'microdistrict' within the PRC's planning practice, on one hand merged with Chinese traditional collective housing, whilst on the other hand, gradually easing planning into more real estate-driven megablock systems. Morris (2013) pointed out that, in traditional European cities, every small plot of land is orientated along the street to promote a sense of equality to ensure that every resident has a view or access to the street. However, with the limited depth of buildings, the short edge of the street also faces its limit, forming a relatively small scale of blocks. Herein the smallness of plot and block remains the essential planning component.

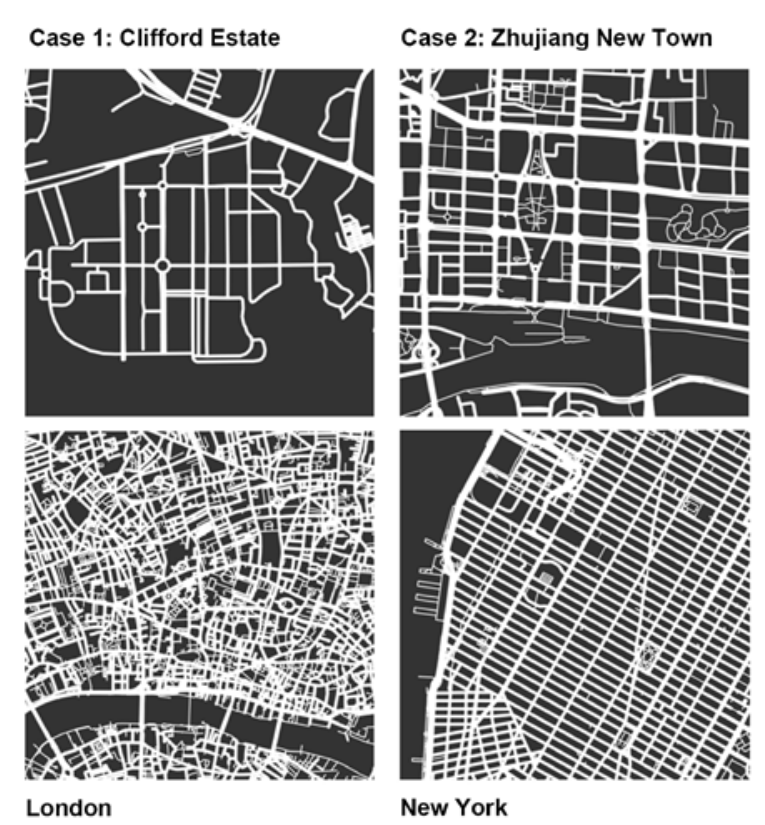

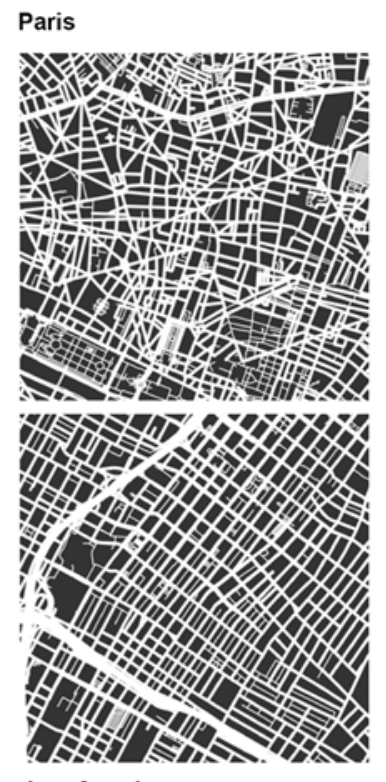

Los Angeles

Figure 3. Density of the road-plot within CMU cases versus Paris, London, New York, and Los Angeles. Road width reflects the hierarchy of the road network. Source: author.

According to Table 2, which shows the Chinese planning code for designing residential blocks, and which also exceeds the European standard. This scaling up of block size implies that policies and technical standards have shifted the understanding of planning scale. In February 2016, the State Council and Communist Party's Central Committee adopted new guidelines that call for; (a) compacter cities with denser networks of streets, (b) more pedestrian and cycling lanes, better public transport, mixed-use zoning, and (c) more green space (Normile, 2016). This new planning policy would indicate a conceptual shift in terms of the 'block'. As Table 2 shows, the increase for all spatial dimensions remains a key difference in the new planning codes, currently advocated by the central government to all the planners and planning schools within China. 


\begin{tabular}{c|c|c|c|c}
\hline Distance & $\begin{array}{c}15 \mathrm{~min} \\
\text { Living zone }\end{array}$ & $\begin{array}{c}10 \mathrm{~min} \\
\text { living zone }\end{array}$ & $\begin{array}{c}5 \mathrm{~min} \\
\text { living zone }\end{array}$ & $\begin{array}{c}\text { Living } \\
\text { neighbourhood }\end{array}$ \\
\hline Walking distance $(\mathrm{m})$ & $800-1000$ & 500 & 300 & - \\
\hline Population & $50,000-100,000$ & $15,000-25000$ & $5,000-12,000$ & $1,000-3,000$ \\
\hline Dwelling number & $17,000-32,000$ & $5,000-8,000$ & $1,500-4,000$ & $300-1000$ \\
\hline
\end{tabular}

Table 2. Renewed planning code in 2018 controlling the size of blocks at multiple levels. Source: Code of Urban Residential Areas Planning \& Design (GB50180-2018)

\section{Research Scope and Methodology}

\subsection{Scope of Study}

As a second part to this paper, the main aim here is to set up an operative framework for urban morphological study of Chinese Megablock development. The emphasis to date has concentrated on the PRD region in its newly established Greater Bay Area Framework, which includes the Guangdong-Hong Kong-Macau Greater Bay Area. The two selected cases referred to herein are the Clifford Estate (CE) in Panyu, and the Zhujiang New Town (ZJNT) in Tianhe. This paper attempts to cover the basic characteristics of megablock examples to demonstrate the CMU model, as well as to conduct options of spatial analysis to test certain qualities of megablocks. These aspects derive from a larger body of research related to mega development, that questions:

(1) In what way can the study of megablock typologies in the PRD deliver better insight in terms of processes and scales of Chinese urbanization?

(2) By studying cases in the Pearl River Delta region of south China, would it be possible to deliver other insight that are able to explain how megablock urbanism shapes Chinese cities with the current urbanization practices' unprecedented speed and scale?

\subsection{Research Methodology}

The research presented herein draws from the discipline of urban morphology to demonstrate the spatial characteristics of the CMU model. By evaluating selected factors and variables, the focus is to understand what CMU actually stands for in urbanization practices.

The CMU empirical methodology takes into account the configurative properties of the urban plot in regard to various factors. As shown in Table 3, megablock properties are expressed using plot dimensions in relation to land use, functional configurations and mobility, each with their distinct variables and measure sets.

Data were collected through multiple sources which included: local government regulatory plans, OpensStreetMaps, open access maps and the statistical data website Map World (https://www.tianditu.gov.cn/), run by China's State Bureau of Surveying and Mapping (SBSM), Google Earth, big data extracted from Baidu Map (map.baidu.com) and real-estate websites including Fang Tianxia (fang.com), Lianjia (lianjia.com), and Centaline Property (centanet.com), field work and proofreading of data conducted during the data collection phase.

Case analysis was conducted using the following steps:

(1) Visualization of the site including building type and 3D model;

(2) Preparing base maps from aerial photos and online maps; 
(3) Mapping the main features and facilities of the case;

(4) Calculation of centrality with sDNA in ArcGIS;

(5) Reflection of data analysis leading to the findings of the study.

In combination, the tentative findings relate both formal and spatial findings that combine to form new datasets with variables.

\begin{tabular}{|c|c|c|c|c|c|}
\hline $\begin{array}{l}\underset{\mathscr{E}}{\mathscr{E}} \\
\stackrel{\Phi}{F}\end{array}$ & 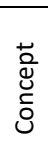 & $\begin{array}{l}\text { Indicator } \\
\text { type }\end{array}$ & Name & Scale & Formula \\
\hline \multirow{7}{*}{ 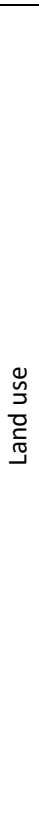 } & \multirow{7}{*}{$\begin{array}{l}\varepsilon \\
\frac{\varepsilon}{2} \\
\frac{0}{2} \\
\frac{1}{\pi} \\
\frac{0}{5} \\
\frac{0}{5}\end{array}$} & \multirow[t]{4}{*}{ Intensity } & Human density & $\begin{array}{l}\text { District } \\
\text { /Neigh- } \\
\text { bourhoo } \\
\text { d }\end{array}$ & $\frac{N b \text { of People }}{\text { surface of selection }\left(m^{2}\right)}$ \\
\hline & & & $\begin{array}{l}\text { Building density } \\
\text { (FAR) }\end{array}$ & $\mathrm{D} / \mathrm{N}$ & $\frac{\text { Floor Area }\left(\mathrm{m}^{2}\right)}{\text { Selection Area }\left(\mathrm{m}^{2}\right)}$ \\
\hline & & & Housing density & $\mathrm{D} / \mathrm{N}$ & $\frac{N b \text { of Buildings }}{\text { surface of selection }\left(\mathrm{m}^{2}\right)}$ \\
\hline & & & $\begin{array}{l}\text { Coefficient of } \\
\text { land occupancy }\end{array}$ & $\mathrm{D} / \mathrm{N}$ & $\frac{\text { Coverage Ratio }\left(\mathrm{m}^{2}\right)}{\text { Selection Area }\left(\mathrm{m}^{2}\right)}$ \\
\hline & & \multirow[t]{3}{*}{ Diversity } & $\begin{array}{l}\text { Subdivision } \\
\text { intensity }\end{array}$ & $\mathrm{D} / \mathrm{N}$ & $\frac{N b \text { of Subdivisions }}{\text { Selection Area }\left(m^{2}\right)}$ \\
\hline & & & $\begin{array}{c}\text { Diversity of } \\
\text { subdivision size }\end{array}$ & $\mathrm{D} / \mathrm{N}$ & $\frac{1}{\operatorname{Cat}} \sum_{i=1}^{\text {Cat }}\left[1-\frac{S_{\text {tot } i} S_{i}^{m}}{A}\right]^{2}$ \\
\hline & & & $\begin{array}{l}\text { Diversity of land } \\
\text { use }\end{array}$ & $\mathrm{D} / \mathrm{N}$ & $\frac{1}{C a t} \sum_{i=1}^{C a t}\left[1-\frac{S_{i}}{S_{i}^{o b j}}\right]^{2}$ \\
\hline \multirow{2}{*}{ 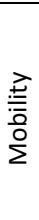 } & \multirow{2}{*}{$\begin{array}{l}\varepsilon \\
\frac{\varepsilon}{2} \\
\frac{1}{2} \\
\frac{1}{0} \\
\frac{0}{5} \\
\frac{0}{5}\end{array}$} & Intensity & $\begin{array}{l}\text { Surface } \\
\text { occupied by the } \\
\text { road network }\end{array}$ & City/D & $\frac{\text { Road Area }\left(\mathrm{m}^{2}\right)}{\text { Selection Area }\left(\mathrm{m}^{2}\right)} * 100$ \\
\hline & & $\begin{array}{l}\text { Connecti- } \\
\text { vity }\end{array}$ & $\begin{array}{l}\text { Connectivity of } \\
\text { the car grid }\end{array}$ & D & $\frac{\text { Interesection Number of Car Grid }}{\text { Selection Area }\left(\mathrm{m}^{2}\right)}$ \\
\hline \multirow[b]{2}{*}{ 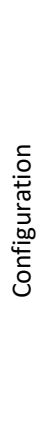 } & \multirow[b]{2}{*}{ 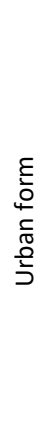 } & \multirow[t]{2}{*}{ Centrality } & Closeness & $C / D$ & $M G L(x)=\frac{\sum_{y \in R_{x}} d_{M}^{E}(x, y) W(y) P(y)}{\sum_{y \in R_{x}} W(y) P(y)}$ \\
\hline & & & Betweenness & $C / D$ & $\begin{array}{c}\text { Betweenness }(x)=\sum_{y \in N} \sum_{z \in R_{y}} W(y) W(z) P(z) O D(y, z, \\
O D(y, z, x)=\left\{\begin{array}{c}1, \text { if } x \text { is on the shortest path from } y \text { to } z \\
\frac{1}{2}, \text { if } x=y \neq z \\
\frac{1}{2}, \text { if } x=z \neq y \\
\frac{1}{3}, \text { if } x=y=z \\
0, \text { otherwise }\end{array}\right.\end{array}$ \\
\hline
\end{tabular}

Table 3. Criteria of urban morphological study, selected by author, reference: Salat (2011); sDNA

\author{
4 Case Studies in the PRD
}

\title{
4.1 Case Study 1: Clifford Estate (CE), Panyu
}




\begin{tabular}{|c|c|c|c|c|c|c|c|c|c|c|}
\hline \multicolumn{7}{|c|}{ Land use } & \multicolumn{2}{|c|}{ Mobility } & \multirow{2}{*}{\multicolumn{2}{|c|}{$\begin{array}{c}\text { Configuration } \\
\text { Centrality }\end{array}$}} \\
\hline \multicolumn{4}{|c|}{ Intensity } & \multicolumn{3}{|c|}{ Diversity } & Intensity & Connectivity & & \\
\hline $\begin{array}{l}\text { Human } \\
\text { density }\end{array}$ & $\begin{array}{l}\text { Building } \\
\text { density } \\
\text { (FAR) }\end{array}$ & $\begin{array}{l}\text { Housing } \\
\text { density }\end{array}$ & $\begin{array}{c}\text { Coefficient } \\
\text { of land } \\
\text { occupancy } \\
\text { (Coverage) }\end{array}$ & $\begin{array}{c}\text { Subdivision } \\
\text { intensity }\end{array}$ & $\begin{array}{c}\text { Diversity } \\
\text { of } \\
\text { subdivision } \\
\text { size }\end{array}$ & $\begin{array}{l}\text { Diversity } \\
\text { of land } \\
\text { use }\end{array}$ & $\begin{array}{l}\text { Surface } \\
\text { occupied } \\
\text { by the } \\
\text { road }\end{array}$ & $\begin{array}{l}\text { Connectivity } \\
\text { of the car } \\
\text { grid }\end{array}$ & Closeness & Betweenness \\
\hline $20,000 / \mathrm{km}^{\wedge} 2$ & $0.8-5.3$ & $\begin{array}{l}\text { Figure } \\
4-A / B\end{array}$ & $\begin{array}{c}\text { Figure 4- } \\
\mathrm{A} / \mathrm{C}\end{array}$ & $\begin{array}{c}\text { Figure 4- } \\
\mathrm{A} / \mathrm{C} / \mathrm{D}\end{array}$ & $\begin{array}{c}\text { Figure 4- } \\
\mathrm{A} / \mathrm{C} / \mathrm{D}\end{array}$ & $\begin{array}{l}\text { Figure } \\
4-C\end{array}$ & $\begin{array}{l}\text { Figure } \\
4-A / C / D\end{array}$ & Figure-5 & $\begin{array}{c}\text { Figure } \\
5 \text {-left }\end{array}$ & $\begin{array}{l}\text { Figure } \\
\text { 5-right }\end{array}$ \\
\hline
\end{tabular}

Table 4. Indicator of case study 1: CE

The Clifford Estate (CE) is a residential compound developed by Clifford Group and is situated within the Panyu District, Guangzhou. It is a mega gated community with a low density occupying over $5 \mathrm{~km}^{2}$; the total Floor Area Ratio (FAR) is 0.8 with Green Ratio (GR) of $75 \%$. Its planning strategies include big environment, large supporting facilities and mega transportation (official website). Since its establishment in 1991, it has sold more than 30,000 units, with a permanent population of more than 100,000 people, and 200,000 owners. Facilities include clubs, stadiums, banks, police stations, fire stations, hospital, shopping mall, international schools, and shuttle bus terminals.

Results from mapping and collected data are crosschecked by empirical field work, shown in Figure 4. CE is regarded as a mega residential development with only parts alongside the arterial road open to the public, and with the majority area enclosed and further sub-divided into 26 gated communities. From the analysis of building changes over time, distinctive characteristics include: early phase development (around 1991-2002) has been driven at the most rapid speed and scale on over $60 \%$ of its total area, with mainly low-density four storage buildings of 0.8 FAR. After that, project number and intensity drop, occupying less land but elevated building floors and FAR, as high as 5.3 for the Clifford Wonderland built in 2017. The land use map shows that there is a limited mix of functions across the whole mega compound. At the same time, through the mapping of its facilities, the results demonstrate an inequitable spatial distribution of its communal resources, alongside insufficient diversity of jobs and business.

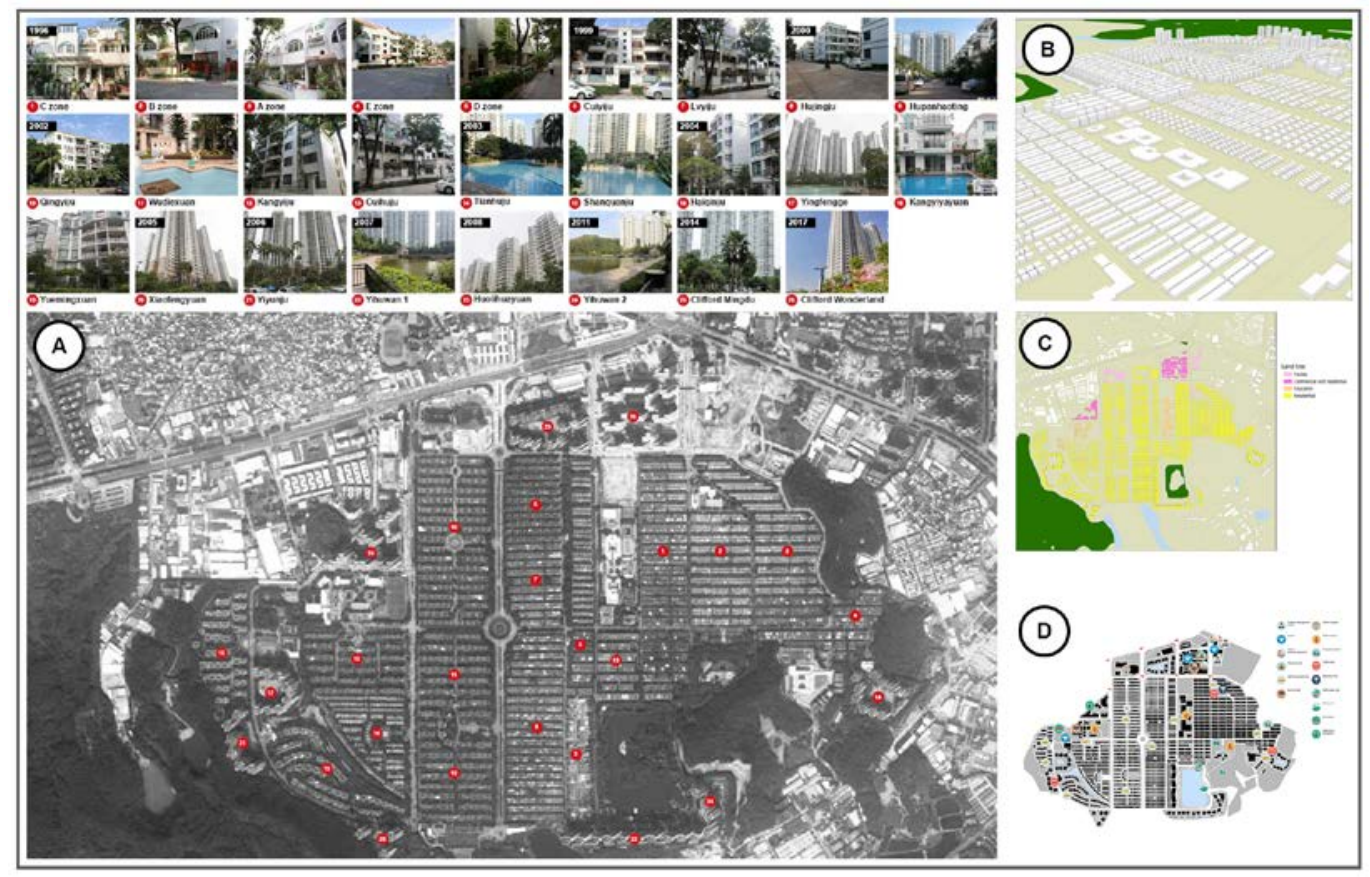


Figure 4. Clifford Estate. A: Aerial photo with building types ordered by constructed year; B: 3D building volume model; C: Land use; D: Main features and facilities. Source: author.

The CMU model's characteristics were further tested by means of other measures. For this effect, we used the Spatial Design Network analysis (sDNA) in ArcGIS to calculate the centrality analysis of closeness (a measure of access) and betweenness (potential flow along a route). The centrality was calculated at two kilometres and ten kilometres network radii, with the former being equivalent to about 25 minutes of walking and the latter to 10 or 20 minutes of driving. Other radii were tested but due to the large size of urban blocks in the region they did not represent the local and mezzo scales well. In the results shown in Case study 1 , the closeness within the internal area of CE is relatively high, indicating relative access internally. However, the closeness at the larger scale indicate that CE is isolated from the larger network. Similar results can be seen for betweenness, which future confirms CE isolation from the urban road network.

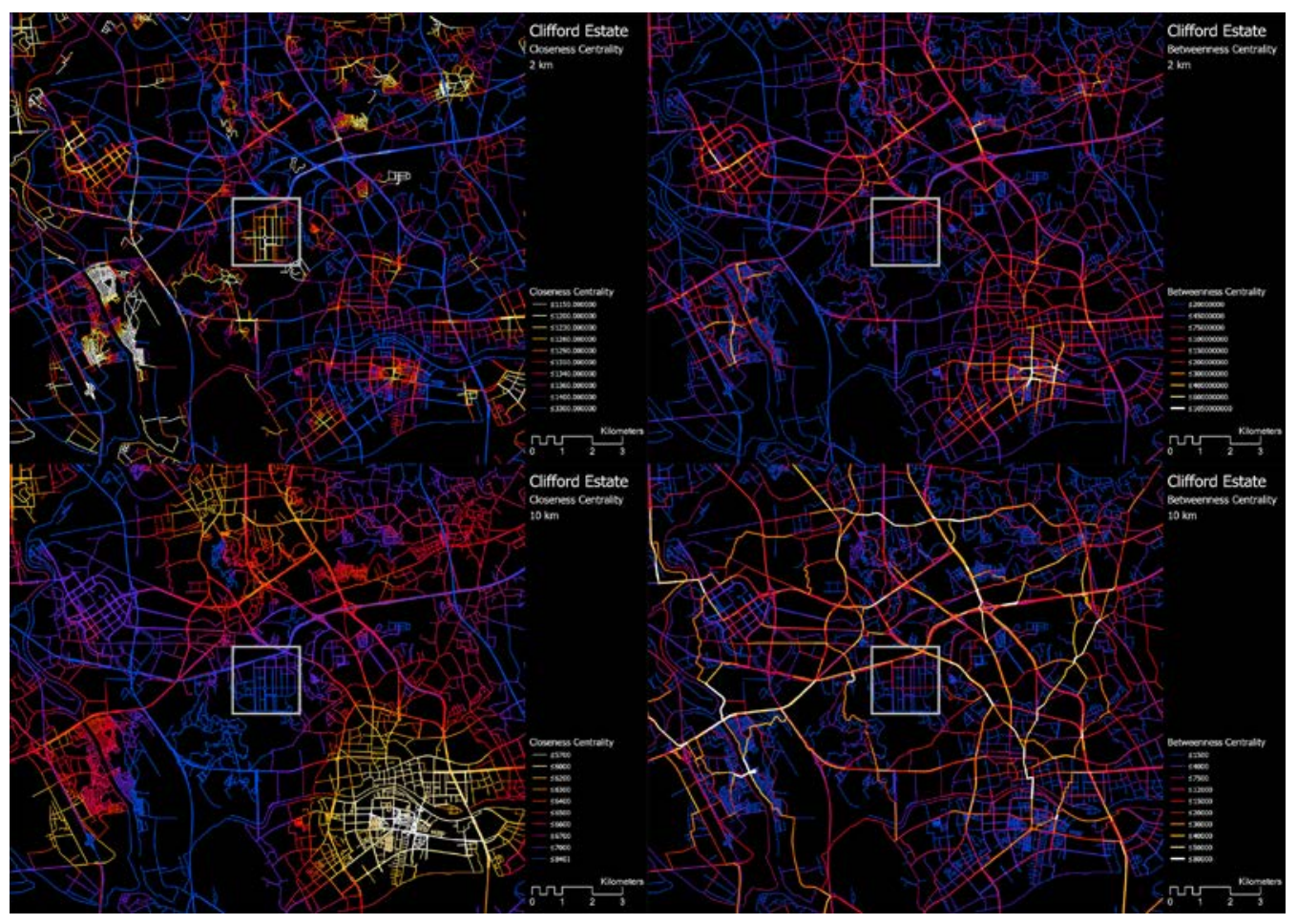

Figure 5. CE centrality analysis of closeness and betweenness in 2/10 km. Source: author.

\subsection{Case Study 2: Zhujiang New Town (ZJNT), Tianhe}

\begin{tabular}{|c|c|c|c|c|c|c|c|c|c|c|}
\hline \multicolumn{7}{|c|}{ Land use } & \multicolumn{2}{|c|}{ Mobility } & \multirow{2}{*}{\multicolumn{2}{|c|}{$\begin{array}{c}\text { Configuration } \\
\text { Centrality }\end{array}$}} \\
\hline \multicolumn{4}{|c|}{ Intensity } & \multicolumn{3}{|c|}{ Diversity } & Intensity & Connectivity & & \\
\hline $\begin{array}{l}\text { Human } \\
\text { density }\end{array}$ & $\begin{array}{c}\text { Building } \\
\text { density } \\
\text { (FAR) }\end{array}$ & $\begin{array}{l}\text { Housing } \\
\text { density }\end{array}$ & $\begin{array}{c}\text { Coefficient } \\
\text { of land } \\
\text { occupancy } \\
\text { (Coverage) }\end{array}$ & $\begin{array}{c}\text { Subdivision } \\
\text { intensity }\end{array}$ & $\begin{array}{l}\text { Diversity of } \\
\text { subdivision } \\
\text { size }\end{array}$ & $\begin{array}{l}\text { Diversity } \\
\text { of land } \\
\text { use }\end{array}$ & $\begin{array}{l}\text { Surface } \\
\text { occupied } \\
\text { by the } \\
\text { road }\end{array}$ & $\begin{array}{l}\text { Connectivity } \\
\text { of the car } \\
\text { grid }\end{array}$ & Closeness & Betweenness \\
\hline $56,000 / \mathrm{km}^{\wedge} 2$ & $3.4-14.9$ & $\begin{array}{l}\text { Figure } \\
6-A / B\end{array}$ & $\begin{array}{c}\text { Figure } 6- \\
A / C\end{array}$ & $\begin{array}{l}\text { Figure } \\
6-A / C / D\end{array}$ & $\begin{array}{c}\text { Figure } \\
6-A / C / D\end{array}$ & $\begin{array}{c}\text { Figure 6- } \\
\text { C }\end{array}$ & $\begin{array}{l}\text { Figure } \\
6-A / C / D\end{array}$ & Figure-7 & $\begin{array}{c}\text { Figure } \\
\text { 7-left }\end{array}$ & $\begin{array}{l}\text { Figure } \\
\text { 7-right }\end{array}$ \\
\hline
\end{tabular}

Table 5. Indicator of case study 2: ZJNT

Zhujiang New Town (ZJNT) is the main component of Guangzhou Tianhe Central Business District (CBD). Tianhe CBD is one of the three national-level CBDs approved by the State Council, and serves the Pearl River Delta Economic Zone. ZJNT has an area of 6.6 square 
kilometres and a total floor area of 13 square kilometres (Fang et al., 2009). In 1992, the municipal government decided to develop a regulatory plan for ZJNT based on Thomas Planning Services, Inc.'s proposal. According to this plan, it would reach a residential population of 170,000 to 180,000 and provides nearly 350,000 to 400,000 jobs.

Mappings and analysis of the ZJNT area are shown in Figure 6. In general, this case shows a higher intensity of development in regard to both speed and scale compared to case study 1. Due to the accessibility of data, the focus of the architectural type is residential developments. Despite its initiation from the early 1990s, the earliest commodity housing compound was built in 1999. Mixed with gated and open communities, buildings, in this case, are high-rise with FAR from 3.4 to 14.9, declining from the central axis on both sides. The mix of land use, diversity and intensity equity distribution of facilities all show higher degrees compared to the CE.

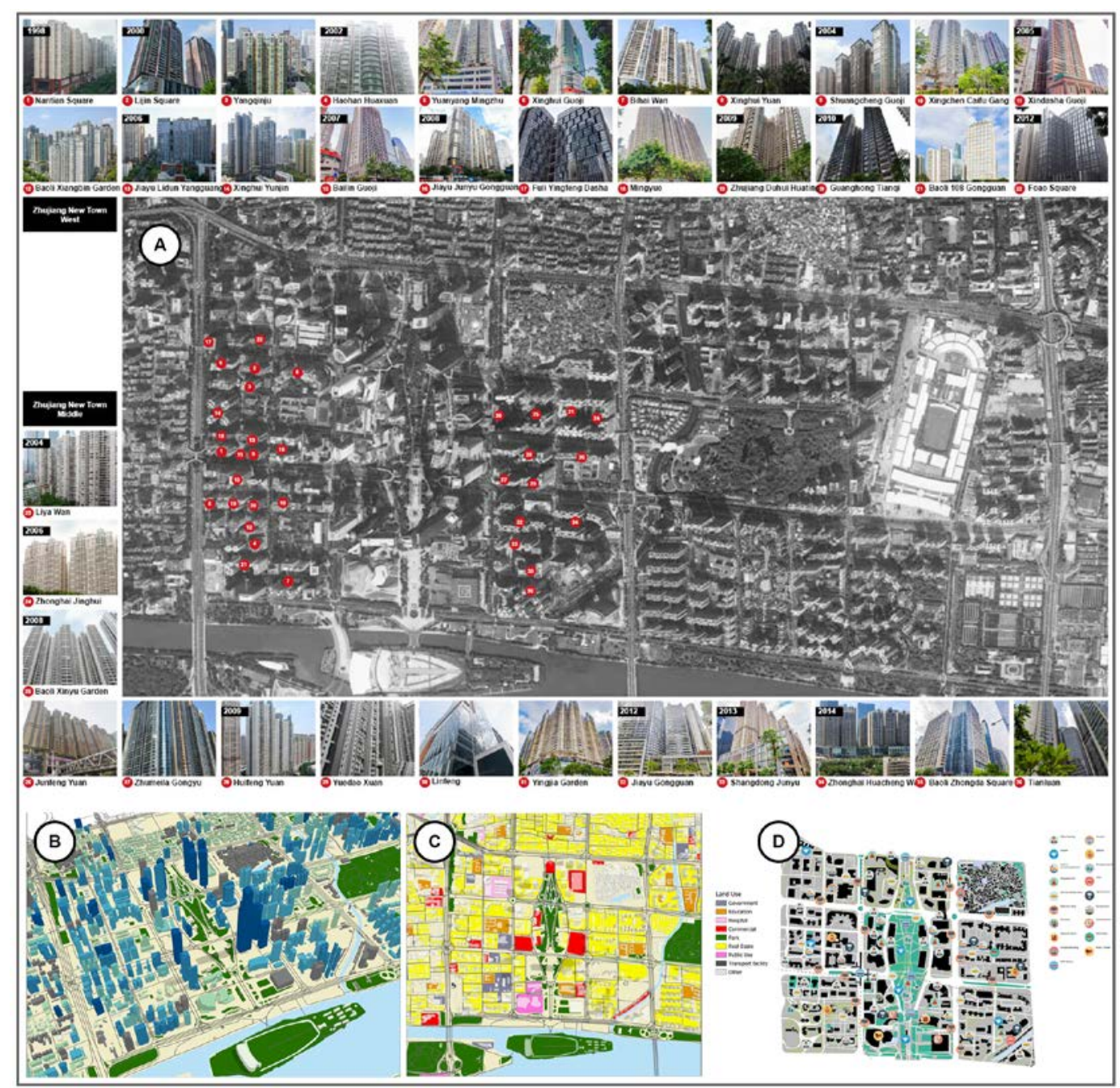

Figure 6. ZJNT. A: Aerial photo with building types ordered by constructed year; B: 3D building volume model coloured by FAR; C: Land use; D: Main features and facilities. Source: author.

The centrality test of ZJNT results demonstrate how the megablock differs from the smaller urban block. In two-kilometre centrality tests, the ZJNT internal network placed at a medium level; however, it revealed a separation from the historical core of the city (Yuexiu), while also creating a new urban node at the lower level. The closeness test at the ten kilometres 
radii indicated a lower level of proximity between spaces in ZJNT compared to old districts (Yuexiu and Tianhe) and showing the influence of modern planning on access at the mezzo level. In addition, the ten-kilometre betweenness test showed that ZJNT is surrounded by a clear super-grid structure, showing a high dependency on arterial roads.

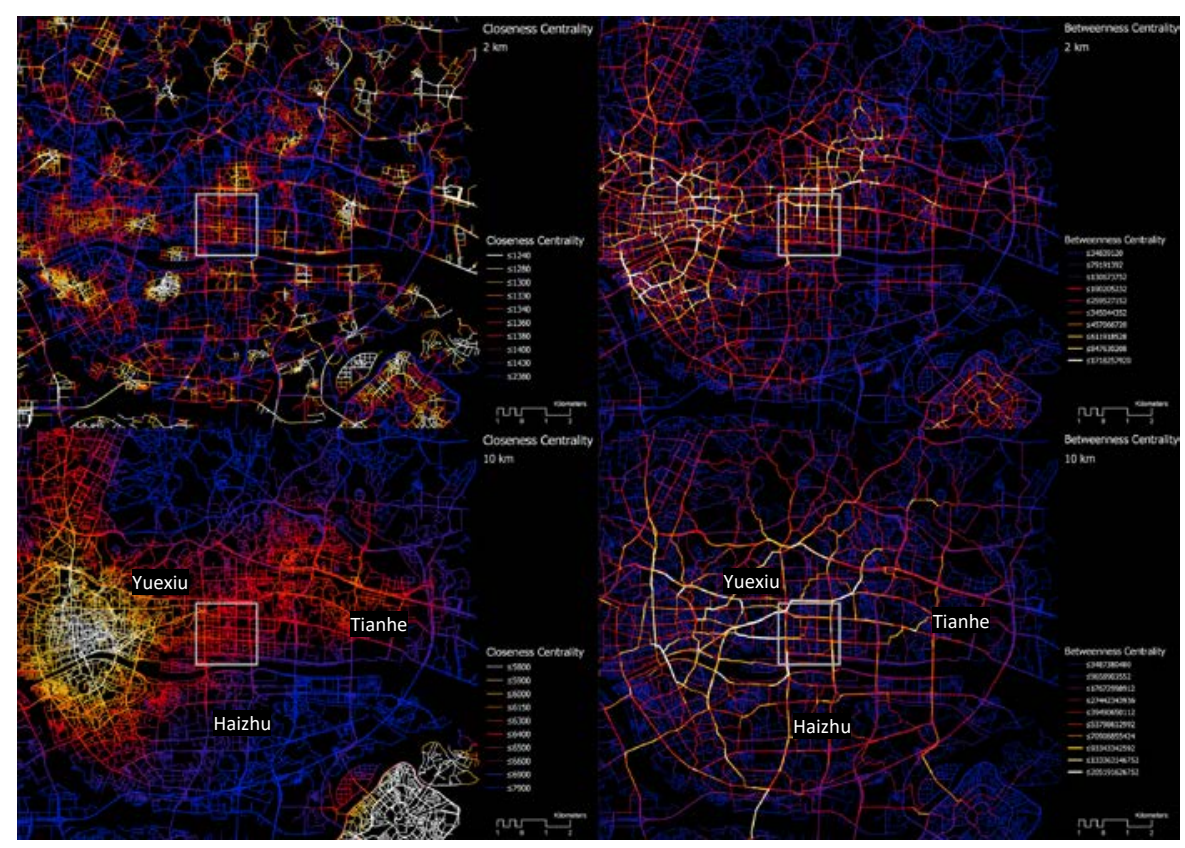

Figure 7. ZJNT centrality analysis of closeness and betweenness in 2/10 km. Source: author.

\section{Conclusion and Discussion}

The results from both cases show that Chinese rapid urbanization has taken place at an unprecedented speed and scale. Development models and tools differ from other countries, and moreover, the scale of the mega forms a contributing planning factor thanks to radical urban growth. Through the study of its evolutionary tract and the two cases shown, CMU reveals intriguing spatial characteristics and qualities that are worth being further investigated. Adaptations and interventions of analysis tools for CMU are essential for the future study. This requires not only new tools, but also new methods as well as conceptual framing. However, current lessons that we could learn from the Chinese rapid urbanization have not raised enough attention from either Western nor Chinese scholars, especially under the nation's exporting strategies, such as for example, "The Belt and Road" initiatives. Future research will continue to explore the phenomenon of $\mathrm{CMU}$, under the perspective of urban morphology, in a more systematic and sustainable direction.

\section{References}

Lu, D. (2006) Remaking Chinese urban form: modernity, scarcity and space, 1949-2005. Routledge.

National Bureau of Statistics of China (2018) Statistical Communique of the People's Republic of China on the 2017 National Economic and Social Development. China National Bureau of Statistic Press. 
Miao, P. (2004) Cancer of urban life: problems of gated communities in China and their solutions. Time Architecture, 5, pp.46-49.

Miao, P. ed. (2013) Public places in Asia Pacific cities: Current issues and strategies (Vol. 60). Springer Science \& Business Media.

Plato. et al. (2000) The Republic, Cambridge: Cambridge University Press.

Wang, J. and Zhang, Y. (2016) Optimization \& control of large-scale urban spatial form based on decision support system for land development intensity. Scientia Sinica (Technologica). Vol. 6.

Guo, L. (2019) "Review of the Studies on Ancient Chinese Urban Form in the Western World Since the Mid-20th Century", Urban Planning International, Vol. 3 (February).

Koolhaas, R. et al. (1995) Small, medium, large, extra-large : Office for Metropolitan Architecture, New York: Monacelli Press.

Patrick, G.(1915) Cities in evolution. London: Williams \& Norgate.

Spengler, O. (1918) The Decline of the West, trans. Charles F. Atkinson.

Mumford, L. (2016) The culture of cities (Vol. 19). Open Road Media.

Frey, H. (2003) Designing the city: Towards a more sustainable urban form. Taylor \& Francis.

Alzraikat, S.A.S. (2016) The garden block: A new model of superblocks towards socioecological cohesion. Illinois Institute of Technology.

Siksna, A. (1997) The effects of block size and form in North American and Australian city centres. Urban morphology, 1(1), pp.19-33.

Shane, D. G. (2014) Block, Superblock and Megablock, A short history. Retrieved from http:// http://www.arcduecitta.it/world/2014/01/block-superblock-and-megablock-ashort-history/

Zhu, J.M. (2004) The Logic of the Development of China's Urban Planning Theories under Market Economy. Journal of Urban Planning Association, 2004(06).

Tortora, A. et al. (2015) Rural landscape planning through spatial modelling and image processing of historical maps. Land Use Policy, 42, pp.71-82.

Yin, G. J.(2010) The Great Leap Forward of City. Wuhan: Huazhong University of Science \& Technology Press.

Kolson, K.L. (2001) Big plans: The allure and folly of urban design. JHU Press.

Sun, H. and Liang J. (2003) Urban Morphological Analysis of Chang'an Lifang in Tang Dynasty. City Planning Review. Vol. 10.

Morris, A. E. J. (2013) History of urban form before the industrial revolution. Routledge.

Normile D. (2016) China rethinks cities. Science 352(6288): 916-918

Salat, S., Labbé, F. and Nowacki, C. (2011) Cities and forms: on sustainable urbanism. CSTB Urban Morphology Laboratory.

Fang, H. et al. (2009) Zhujiang New Town Planning and Development Review. City Planning Review. Vol.S2 